\title{
O cuidado ao portador de transtorno psíquico na atenção básica de saúde
}

\author{
Health care given to people suffering of mental \\ disorders assisted by basic health attention
}

Mércia Zeviani Brêda 1

Lia Giraldo da Silva Augusto 2

\footnotetext{
1 Departamento de Enfermagem, Universidade Federal de Alagoas. Fundação Oswaldo Cruz. Rua dos Coelhos 450/10 andar, 50070-550, Recife PE. mzb@fapeal.br

2 Departamento de

Estudos em Saúde Coletiva,

Centro de Pesquisa

Ageu Magalhães.

Fundação Oswaldo Cruz.
}

\begin{abstract}
The aim of this study is to understand how health care is given by the basic health attention to people who have mental disorders. It was carried out in a suburb, assisted only by The Family Health Program, in the outskirts of the borough of Maceio, in the state of Alagoas, Brazil. This study searched for the material for this comprehension in this scenery and patient's experience reports their families and professionals of health. A qualitative approach of the study case was based on Lüdke and André's theory for data collection and Minayo's theory for final analysis. This study case showed that the health care to people given by the basic health attention who have mental disorders had been medicated, hospitalised and fragmented. The professionals of health, as well as, the families have reproduced the committal's logical, that is reinforced for insufficiency and inefficiency of the mental health public system. The Family Health Program, in this case, isn't able to change the logical centred in the biomedical model, its way of care isn't coherent with the principles of Sanitary and Psychiatric Reform. The penetration of the professionals in social nets is still very small and the dynamic of theirs actions is individual and passive. Forms of approaches founded in listening, in welcome, and in linking are rarely used.
\end{abstract}

Key words Health care, Basic health attention, Mental disorders, Family Health Program
Resumo Este trabalho objetiva compreender o cuidado prestado em saúde aos portadores de transtornos psíquicos na atenção básica em saúde. Foi desenvolvido em um bairro periférico do município de Maceió, de exclusividade do Programa de Saúde da Família. Buscou nesse cenário e nos relatos de experiência dos portadores, seus familiares e profissionais de saúde, o material para essa compreensão. Utilizou uma abordagem qualitativa de estudo de caso referendada por Lüdke \& André e Minayo para a análise final. Revelou que o cuidado ao portador psíquico na atenção básica em saúde tem sido medicalizado, hospitalar e fragmentado. Os profissionais de saúde, assim como as famílias têm reproduzido a lógica do internamento psiquiátrico, que é reforçada pela insuficiência e ineficácia do sistema público de atenção em saúde mental local. O Programa de Saúde da Família, neste caso, não tem sido capaz de mudar a lógica da atenção centrada no modelo biomédico e, sua forma de cuidar em saúde não se coaduna com os princípios da Reforma Sanitária e Psiquiátrica. Sua penetração nas redes sociais é tímida e a dinâmica das ações é passiva e individual. Formas de abordagem baseadas na escuta, no acolhimento e no vínculo são raramente utilizadas.

Palavras-chave Cuidado em saúde, Transtorno psíquico, Atenção básica em saúde, Programa de Saúde da Família 


\section{Transtornos psíquicos: problema de saúde coletiva}

Em 1989, a Organização Pan-Americana de Saúde alertava para o fato de que a América Latina enfrenta uma pandemia de transtornos psiquiátricos, que terá: importantes repercusiones en el desarrollo social de los países latinoamericanos y en la planificación y prestación de serviços de psiquiatría e salud mental. (Levav et al., 1989).

Pesquisas recentes evidenciam a dependência crescente e cada vez mais precoce de álcool e de drogas entre os jovens brasileiros, acarretando perda da produtividade, mortes prematuras e gastos substanciais com tratamento (Galduróz, apud Ministério da Saúde do Brasil, 1999).

As internações psiquiátricas no Brasil, não obstante seus danos, vêm apresentando um dos maiores gastos com a rede hospitalar do Sistema Único de Saúde. Os leitos, na sua maioria $(78,8 \%)$, privados e contratados pelo setor público, apresentam internações longas, chegando a alcançar em média 55,6 dias de duração (Ministério da Saúde do Brasil, 1999).

A situação torna-se mais preocupante caso se considere o crescimento absoluto de habitantes, o impacto psiquiátrico causado pela crescente concentração de renda, e a diminuição do acesso aos bens e serviços distribuídos pelo Estado, que em última instância, caracterizamse num processo destrutivo da qualidade de vida e saúde (Levav et al.,1989).

O resultado mais drástico desse modelo econômico tem sido a desigualdade social que divide o país em regiões desenvolvidas e subdesenvolvidas. No Nordeste, mais concretamente em Alagoas, exemplo de região subdesenvolvida, a crise político-econômica dos últimos anos fez com que o Estado perdesse sua capacidade de investimento em infra-estrutura e promoção de políticas sociais (Veras, 1997).

Em relação à assistência em saúde mental, no ano de 1998, segundo informações do Movimento Nacional de Luta Antimanicomial (1999), Alagoas foi o "terceiro estado do país que mais gastou com internações psiquiátricas", o que pode ser considerado paradoxal num Estado que possui 2.633.339 habitantes (IBGE, 1996).

Em Maceió, capital do estado, não há registros de internações psiquiátricas em hospitais gerais. Vinte e cinco por cento das Autorizações de Internações Hospitalares (AIHs) são gastas com internação psiquiátrica. Dos 1.450 leitos psiquiátricos, a maioria ( $80 \%)$ é do setor privado e com um custo médio de $\mathrm{R} \$ 800,00 /$ mês por paciente (Coordenação de Saúde Mental, 1998).

Essa situação coloca um grande desafio aos pesquisadores, profissionais de saúde, gestores, órgãos formadores e usuários dos serviços de saúde do estado e do município. Cabe a eles, portanto, de forma democrática e pactuada, articular saberes e desenvolver estratégias de mudanças no modelo assistencial e na legislação em saúde mental para que, paulatinamente, se observem mudanças culturais secularmente enraizadas na sociedade.

\section{Movimentos de mudança}

No Brasil, nas últimas décadas, um conjunto de iniciativas políticas, científicas, sociais, administrativas e jurídicas têm lutado para transformar a compreensão cultural e a relação da sociedade com as pessoas que apresentam transtornos mentais. Este processo resultou na provisão de incentivos para o uso de recursos extra-hospitalares, prezando pela manutenção do portador de transtorno mental em seu meio familiar e comunitário. Essas iniciativas, aliadas à divulgação pelos meios de comunicação, da precária assistência psiquiátrica hospitalar, com violação dos direitos civis dos pacientes, têm criado, junto à opinião pública, o consenso quanto à necessidade de mudança (Melman, 1999).

Em Maceió, acredita-se haver uma percepção de emergência na criação de modelos substitutivos e descentralizados, apoiados pelo governo local. Em 1998, foram implantados três centros de assistência psicossociais, com a proposta de implantação de outras variedades de serviços especiais articulados à rede básica de saúde, com destaque ao Programa de Saúde da Família/PSF (Coordenação de Saúde Mental, 1998).

Vale salientar que, nesse município, essa modalidade de atenção básica (PSF) constituise, hoje, na principal porta de entrada do sistema de saúde, o elo mais próximo entre as unidades assistenciais, família e a comunidade (Maceió, 1999).

Para Campos (1992), um projeto de reinserção social dessa parcela da população, que apresenta transtornos mentais, exigiria que a rede básica de saúde fosse habilitada a interromper essa ciranda infernal de crise-internação-crise. 
A Declaração de Caracas, redigida em 1990, também, reforça a idéia da reestruturação da atenção psiquiátrica vinculada à Atenção Primária à Saúde, permitindo a promoção de modelos substitutivos concentrados na comunidade e integrados com suas redes sociais, preponderando a manutenção do doente em seu meio social (Kalil, 1992).

Tal idéia tem dupla repercussão: por um lado, o hospital psiquiátrico deixa de ser o componente central da atenção psiquiátrica e, por outro, propõe que os serviços comunitários passem a ser o principal meio para se obter atendimento.

Outro aspecto subjacente a este é a proposta da transformação do conceito de doença mental na noção de existência - sofrimento. Para Amarante (1999) isso significa que, deixamos de nos ocupar da doença e nos ocupamos dos sujeitos. $O$ tratamento e a instituição do cuidado deixam de significar apenas a prescrição de medicamentos, a aplicação de terapias, para tornar-se um ocuparse cotidiano do tempo, do espaço, do trabalho, do lazer, do ócio, do prazer, do sair, da organização de uma atividade conjunta (...).

O que envolve construir uma nova forma de cuidado que, não seja mais de exclusão e isolamento, mas, pautada, sobretudo, na democracia, solidariedade e tolerância em relação à diferença. Uma forma de cuidado que se revele numa atitude de colocar atenção, mostrar interesse, compartilhar e estar com o outro com prazer; não numa atitude de sujeito-objeto, mas de sujeito-sujeito, numa relação não de domínio sobre, mas de com-vivência, não de intervenção, mas de interação (Boff, 1999).

Há que se considerar que, apesar do importante papel que os serviços de atenção básica assumem na concretização ou inviabilização da transformação do cuidado prestado aos portadores de transtornos mentais, raros são os estudos que abordam este tema.

Dentre eles, está o de Amaral (2000) onde revela que a rede básica de saúde em Campinas (SP) não tem contribuído para redução das reinternações, afastando o portador de sua rede social. Aponta como principais causas: a pequena inserção das equipes de saúde na comunidade local, o não uso de novos equipamentos/recursos de saúde mental (oficinas, grupos etc.) e a ausência de articulação intersetorial.

Oliveira (1998), em um estudo sobre atendimento médico em um Centro de Saúde, observou que a conduta mais freqüente dos médicos em relação ao adoecimento psíquico, qual- quer que fosse o problema, era medicar com benzodiazepínicos.

Outro que chama atenção é Danese (1998), que se deparou com pessoas que faziam uso constante de psicofármacos numa população atendida pelo PSF e, que não identificavam o serviço de saúde como o lugar onde poderiam ser ajudadas. Diante do descuido do serviço de saúde essas pessoas procuravam a religião para o enfrentamento de seus problemas. Evidenciando um conflito culturalmente construído, em que o serviço de saúde utiliza tratamentos tecnicamente fixos, ao passo que, os pacientes buscam mais do que o alívio dos sintomas, explicações significativas e tratamento psicossocial da doença.

A esse respeito Kleinmann (1978) se refere a sistemas de cuidado à saúde - tarefas culturalmente adaptativas em face da doença. Estes sistemas estabelecem relações entre as crenças sobre causação, experiências de sintomas, decisões e avaliação sobre tratamento e práticas terapêuticas. Contém três arenas: a popular, a folclórica e a profissional. Cada uma utiliza-se de um "modelo explicativo" que congrega sistemas específicos de conhecimento e valores. De acordo com essa concepção, o modelo explicativo biomédico pode estruturar uma visão clínica, centrada no atendimento médico, na qual a doença (disease) é localizada dentro do corpo do doente e a assistência é vista como o tratamento orgânico. E, o modelo explicativo popular pode localizar o problema (illness) na família e o alvo do tratamento envolverá muito mais do que o corpo do paciente.

A partir destas informações, pode-se trabalhar com duas pressuposições. Primeiro, que existe uma dicotomia no PSF, entre o modelo biomédico e o modelo popular de atenção. Segundo, que este programa, apesar de se constituir numa nova proposta de reorganização da atenção em saúde, não supera o modelo biomédico dominante.

Nesse sentido, buscar compreender a dimensão social do cuidado, a inserção das redes sociais na atenção básica em saúde e vice-versa, poderá contribuir com o debate de novos modelos assistenciais. Sabendo-se que o PSF aproxima-se do cotidiano destas redes, esta pesquisa buscou responder: Como é prestado o cuidado em saúde ao sujeito portador de transtorno psíquico num território de abrangência do Programa de Saúde da Família? 


\section{Trajetória metodológica}

Para responder esta pergunta, utilizou-se da Abordagem qualitativa de estudo de caso, referendada por Lüdke \& André (1986). Foram empregadas técnicas de entrevista semi-estruturada, de observação direta e, registro em diário de campo. Para a análise dos dados, foram considerados os pressupostos de Minayo (1992). A partir da transcrição e leitura repetida dos relatos destacaram-se e recortaram-se os trechos mais significativos das experiências dos sujeitos e, convencionou-se chamá-los de "unidades significativas". Essas unidades foram separadas por temas que guardavam íntima relação com os objetivos e pressupostos da pesquisa. Da perspectiva da equipe, os temas versam sobre os transtornos psíquicos mais freqüentemente percebidos, a forma de cuidado prestada aos sujeitos acometidos e sugestões de como lidar com o problema. Da perspectiva dos portadores, foram observadas a história de vida e de adoecimento, as formas de enfrentar o problema e o tipo de cuidado prestado pelos familiares e equipe do PSF. Destes temas emergiram as categorias orientadas, sobretudo, na compreensão do cuidado ao portador de transtorno mental num espaço social particular.

\section{O cenário da pesquisa}

Trata-se da comunidade do Pontal da Barra, como é habitualmente chamada, localizada entre o mar e a lagoa, no litoral sul de Maceió, e separada do resto da cidade por vazios urbanos e pela indústria cloroquímica Salgema.

Sua história remonta a um tempo em que o bairro era "terra de índio", época em que formava uma aldeia, no sentido de uma só família, e onde a solidariedade fazia parte das relações familiares e de vizinhança. A implantação da Salgema em 1976, a integração da população com o mercado de trabalho urbano, e o aumento do fluxo de turistas contribuíram para introduzir no Pontal a perspectiva da rua - da individualização - rompendo com a perspectiva do bairro. O Pontal era uma bucólica vila de pescadores (hoje se constitui em um bairro de periferia urbana de Maceió), que apesar das transformações de ordem econômica que vem sofrendo, preserva ainda suas atividades tradicionais de subsistência: a pesca e o artesanato (Vieira, 1997).

Possui uma Unidade de Saúde da Família, conta com um médico, enfermeira, odontólo- go, auxiliares de enfermagem, agentes comunitários de saúde e atendentes. Oferece 100\% de cobertura às 744 famílias residentes, onde 99\% destas dependem exclusivamente do Sistema Único de Saúde (Secretaria Municipal de Saúde de Maceió, 1999).

Em julho de 2000, o mural da Unidade de Saúde expunha as cinco principais doenças referidas pela comunidade no ano anterior: $69 \%$ hipertensão, 15\% alcoolismo, 13\% diabetes, 2\% epilepsia e $1 \%$ tuberculose.

Em relação aos problemas de saúde mental, além da alta prevalência de alcoolismo, sabe-se que o distrito de Saúde a que pertence este bairro foi responsável por $15 \%$ das internações psiquiátricas no ano de 1999 e, não possui nenhuma referência para assistência em saúde mental (Coordenação Municipal de Saúde Mental, 1998). A unidade de saúde local contou com o atendimento semanal psiquiátrico que se extinguiu na primeira semana da etapa de trabalho de campo desta pesquisa.

\section{Sujeitos da pesquisa}

São sujeitos desta pesquisa: os portadores de transtorno psíquico residentes nessa comunidade e os profissionais de saúde da família que nela trabalham. A escolha desses dois grupos de sujeitos se baseou na tentativa de captar a perspectiva de quem, pelo menos a princípio, presta formalmente o cuidado e de quem o recebe. Os personagens ganharam pseudônimos por questões éticas.

\section{O depoimento da equipe do Programa de Saúde da Família}

\section{1) Sobre a existência, tipo e intensidade de transtornos psíquicos com os quais a equipe se depara no seu dia a dia}

O conteúdo da fala da equipe destaca o alcoolismo, a depressão, o uso indiscriminado de psicofármacos e as recentes tentativas de suicídios como os problemas psíquicos mais prevalentes.

O alcoolismo, infiltrado na maioria das famílias do Pontal, tem gerado dor e sofrimento aos dependentes e aos que convivem com ele. É comum o relato de mulheres que "sofrem dos nervos" ou que desencadeiam um processo de hipertensão arterial devido à presença de al- 
coolistas na família. Tem gerado conseqüências altamente destrutivas, como é o caso de recentes tentativas de suicídio. Os fatores desencadeantes apontados são: a falta de oportunidade de emprego, a atividade pesqueira, a exposição precoce ao álcool no ambiente familiar e a abertura constante de bares na comunidade.

A utilização indiscriminada de medicação psiquiátrica é "denunciada" na fala de uma atendente que há vinte e um anos reside no Pontal: "Aqui o pessoal toma o remédio controlado direto!” Relacionada à automedicação, pode indicar a dificuldade de acesso da população aos serviços de saúde, a ação iatrogênica das prescrições médicas ou, o que é pior, o uso como válvula de escape de crises vivenciais como o desemprego, o alcoolismo, problemas familiares, dentre outros.

\section{2) Sobre o tipo de assistência prestada aos portadores de transtornos psíquicos}

Depara-se com uma dinâmica assistencial individual, passiva, pouco criativa, centrada na internação psiquiátrica e na medicalização dos sintomas. Uma conduta freqüente é a indicação de benzodiazepínicos, claramente expressa na fala de um agente de saúde: “é sempre o mesmo medicamento que o doutor passa, sempre Diazepan".

A internação psiquiátrica é reforçada pela insuficiente rede substitutiva de atenção em saúde mental no município. Enquanto no cenário nacional e internacional a centralidade do hospital na assistência a estes portadores está sendo fortemente rejeitada. Nessa comunidade os depoimentos desses profissionais revelam uma tendência oposta: "A gente sempre encaminha para o Bebedouro [referência de outro distrito sanitário] (...) sempre encaminha pra algum canto (...)". Estes encaminhamentos, por sua vez, dificilmente se concretizam, o agente de saúde revela: "fica difícil pra gente dizer - 'vá pra tal canto que você vai ser atendida lá', fica difícil. Acaba internando é mais fácil”.

A não comunicabilidade entre o Programa Saúde da Família e os serviços de referência em saúde mental é sentida, porque a Secretaria sempre fala desses "CAPS" mas, sinceramente! A gente já encaminhou tanta gente lá e não sabe nada (...) eu não sei o que eles fazem lá, não dá um retorno, a gente não sabe nem se a pessoa tá seguindo o tratamento ou não tá. No dia a dia não funciona (...) A burocracia é muito grande até nas coisas pequenas, por exemplo: marcar consulta por telefone.

Bandeira (1993) alerta para o fato de que a desinstitucionalização falha quando se depara com a falta de apoio financeiro suficiente para criar serviços substitutivos, de formação profissional, de preparação e engajamento da comunidade no acolhimento ao doente, de atendimento permanente e, de comunicabilidade entre os diferentes setores.

Quanto ao relacionamento da equipe com a população em geral e com os que vivenciam o processo de adoecimento psíquico, constatase que os agentes de saúde foram os únicos membros da equipe que visitaram os portadores em seu domicílio e, sua atitude se diferenciava do restante da equipe por ser mais cordial, compreensiva e afetuosa.

A passividade do programa, característica do trabalho de demanda espontânea, que não é o seu propósito, fica evidenciada nesta fala: “Esse Márcio, eu nem sabia que ele tinha esse problema, a mãe dele nunca chegou aqui pra mim, pra conversar, nunca!".

Para o enfermeiro, a atitude de ouvir o outro perde prioridade diante das exigências burocráticas e administrativas da Unidade de Saúde: "Não tenho tempo disponível para ficar escutando, tô cheia de coisas pra fazer na Unidade".

Carl Rogers (1971) chama este processo do homem se relacionar com outros seres humanos de "misterioso ofício". A razão disso reside no fato de que as pessoas dificilmente conseguem estabelecer uma comunicação interpessoal satisfatória, mas quando conseguem sentem-se extremamente compensadas. Para ele, alguns elementos como a disposição positiva em ouvir e o interesse em compartilhar sentimentos e idéias são imprescindíveis para uma comunicação rica e engrandecedora entre as pessoas.

3) A equipe aponta algumas sugestões de melhoria de assistência a estes portadores

Percebe-se, porém, ser tímido o desejo e a busca de penetração do programa nas redes sociais, limitando-se, na maioria das vezes, ao relacionamento com o Conselho Gestor de Saúde e escola municipal local.

A psiquiatra é uma ausência sentida. $\mathrm{O}$ desejo de que a Unidade volte a contar com esse profissional foi manifestado por todos os profissionais entrevistados. Para os portadores re- 
presentou a perda de um acompanhamento terapêutico que não foi substituído por outro. Mesmo entre as pessoas que se dispõem a procurar os serviços de referência, há a queixa da grande distância e dificuldade de transporte. Ficam a mercê de sua própria sorte, já que todos dependem exclusivamente do sistema público de saúde e esperam dele a sensibilidade e a atenção para a solução dos seus problemas.

São dadas outras sugestões, como uma melhor articulação entre setores, ampliação multiprofissional da equipe, desenvolvimento de trabalhos de grupo e a necessidade de preparo profissional para lidar com os portadores de transtorno psíquico. Um Agente de Saúde, que trabalha com esta comunidade desde a implantação do Programa avalia: A gente não tem preparo nenhum (...) a Secretaria dá curso, mas não é um curso (...) é muito assim (...) eu acho que depende de cada realidade de cada bairro, né? Porque o pessoal do Pontal é por causa do álcool, outros "pode" não ser por causa do álcool, né? Então eles não "trabalha" com a terapêutica daquilo, foge muito à realidade, né?(...) A gente quer saber como se comportar diante do paciente (...) A gente precisa ser preparado para saber como agir com eles(...) a gente não sabe.

A fala do sujeito a ser cuidado, por sua vez, reforça e insere novos elementos para reflexão e análise da relação destas pessoas com os serviços de saúde.

\section{O depoimento do portador de transtorno psíquico}

1) As histórias de vida e de adoecimento psíquico revelam experiências que favorecem rupturas na vida psíquica. Quebras de vínculos afetivos, abandono na infância e violência familiar marcam a trajetória dessas pessoas. A violência sofrida na infância e juventude, por vezes, se estende para a vida adulta.

Segundo Agudelo (1997) a "ordem violenta" manifesta-se por meio da penetração e instalação da violência em todos os cenários da vida social, inclusive nas relações familiares. É ubíqua e absoluta, substituindo a palavra e o argumento, silenciando a razão, criando heróis e normas, regulando os tempos, os espaços, os gestos, as palavras e as idéias, destruindo o gozo, os sonhos e a vida. É a intolerância à diferença e o império do medo e da impunidade. Conforma uma rede por vezes invisível, mas sempre presente. É uma maneira, um clima, uma maneira não escolhida de ter que andar pelo mundo.

Para dona Maria Rosa, 49 anos, o sofrimento vivenciado sob essa "ordem" se expressa bem neste pequeno relato: Eu fui criança sofri demais, eu nunca fui à escola (...) fui criança sofrida, meu pai foi um carrasco (...) eu tinha 5 ano, ele cuspia na minha cara (...) levava pisa de cangaço de coro cru (...). Bom, daí eu fui crescendo, né? Quando foi com 12 anos fui mãe(...) fiquei criando fio sem pai (...) sem se casá (...) fui vendê o corpo pra dá o de comê Às minhas filhas e, fui sofrendo demais, né?

No caso de Gal (47 anos) que após ter sofrido a violência e a incompreensão dos pais e do marido, por acréscimo, perde também a guarda dos filhos. Segundo ela: Eu fiz um esforço sobrenatural pra cuidá dos meus filho, mas eu não tive essa condição, não me deram essa condição, e de tanto maltrato que eu tive dentro de casa, minha mãe aproveitou a minha ausência (...) pegô os meus filho junto com a minha irmã, apanhou um táxi e levou (...) me desesperei, eu me desesperei, eu perdi minhas cria, né? Eu queria criar os meus filho, e eu perdi os meus filho dessa forma: - foi arrancado de mim. (...) ouvia o choro deles, quando na hora da mamada, ouvia o choro deles na hora do banho, tudo, tudo ficou no meu subconsciente, né? (...) eu tenho certeza que o meu problema de saúde começou daí.

Para dona Marli do Véio, de aproximadamente sessenta anos, nada a marcou mais do que o abandono na infância: (...)eu nasci, minha mãe me teve, por volta de seis meses ela morreu (...) meu pai morreu eu só tava com três anos. Não conheci pai, não conheci mãe, não conheci nem avó, nem avô nem ninguém. (...)Aí, fiquei na casa de um, na casa dos outros. (...)até esmola eu pedi pra comer(...) Nem tive carinho de mãe nem de pai. Amor só pode dar quem recebeu, né?

$\mathrm{O}$ adoecimento psíquico de um familiar, comumente, associado à incapacidade da família em se prover do sustento adequado, faz com que as dificuldades se acumulem e, a rede do sofrimento se amplia. Heloísa (30 anos), que perdeu a mãe há pouco tempo, tem o pai e o irmão vivenciando o adoecimento psíquico revela: (...) saber que a minha mãe tava com aquela doença foi como se o mundo tivesse caído. Daí, me arrasô mesmo, psicologicamente eu tô arrasada (...) pra completar, meu pai, depois que a minha mãe morreu, começou a se arrasá (...) aí, me arrasou também, eu ultimamente não tenho conseguido nem dormir, minha cabeça queima, é 
a maior agonia, preocupada com tudo, desempregada (...) eu penso muito, me apareceu gastrite, ansiedade, eu não me alimento bem, não durmo, tudo eu boto na cabeça, fico preocupada pensando na minha vida (...) eu não tenho amiga, vivo dentro de casa, nem na praia eu vou, não saio nem do lado de fora. (...) não consigo comê começo fazer uma coisa não consigo (...) então minha cabeça começa a martelar.

Para Teles (1992), quando para o ser humano existe a necessidade de prover-se do sustento adequado e esta condição lhe é tirada, gera dificuldades materiais concretas que podem levá-lo ao adoecimento psíquico.

A necessidade da inserção no mercado de trabalho é freqüentemente expressa por estas pessoas. $\mathrm{O}$ desemprego, presente entre mais da metade dos entrevistados, os tem privado desta oportunidade. Resultado cruel do modelo econômico vigente no país, fragiliza o homem e não deve ser desconsiderado, ainda mais, entre os que sofrem as influências da realidade subjetiva e objetiva. Caracteriza-se em verdadeiro descuido social.

Para Dona Gilda (50 anos), por exemplo, parte do seu desencanto pela vida e o de muitas outras pessoas em Alagoas, começou quando teve que pedir o desligamento voluntário de uma função de merendeira que exercia no Estado, (...) depois que eu perdi meu emprego, que eu fiquei desse jeito (...) O Suruagy foi muita coisa, ele fez muita coisa ruim, ele foi muito cruel, muita gente se acabou-se [suicidou-se] (...) Passei mais de 6 meses, eu não fazia nada, não dormia, não tomava banho, não queria comê. Pra tomá banho precisava que os meus filho me desse. Me jogasse dentro do banheiro e me desse. (...) o dia que eu não dava 3 entrada no Pronto Socorro eu não dava nada (...) eu só dormia as custa do remédio do Pronto Socorro.

A falta de independência financeira causada pelo desemprego é geradora de ainda mais sofrimento: Hoje em dia eu dependo (...) se eu quero ir daqui pra cidade eu tenho que pedi - "Ô José, não tem não meu filho dois passe que me arranje?” (...)Daí, eu corto tudo e não saio pá canto nenhum, além do mais os meus fio me dá um bocado pá comê e vai dá mais dinheiro de modo eu passeá? (...) Repare se não é uma coisa revoltante na vida da pessoa? Cada um pense e, bote o sentido de si que não é uma coisa revoltante?

2) Dentre as formas de enfrentamento do adoecimento psíquico, a internação em instituição psiquiátrica é a mais usada por estas pessoas e seus familiares. Para Damião (62 anos) as longas e sucessivas internações foram, ao mesmo tempo, uma forma de tratamento e causa de sofrimento. Ele mesmo expressa a extensão da sua dor: fiquei doente (...) fiquei doente (...), eu era pobre (...) eu era pobre (...), eu era doido (...) eu era doido, (...) eu sofri dos pulmão (...) sofri dos nelvos (...) não teve cura (...) não teve cura mesmo (...) aí, eu era com trinta anos e tava sofrendo e, com aquela esperança. Aí eu fiquei sofrendo (...) com aquela esperança (...) eu estava sofrendo, eu estava sofrendo (...) eu estava sofrendo até os sessenta anos.

Goffman (1961) alerta para o fato de que na internação psiquiátrica as pessoas: podem descobrir-se numa "atadura" muito especial. Para sair do hospital ou melhorar sua vida dentro dele, precisam demonstrar que aceitam o lugar que lhes foi atribuido, consiste em apoiar o papel profissional dos que parecem impor essa condição(...) servidão moral auto-alienadora(...) onde podem ser esmagados pelo peso de um ideal de serviço que torna a vida mais fácil para todos nós.

É o caso de dona Maria Rosa (49 anos) que também, passou boa parte da sua vida internada. No seu depoimento ela diz: (...) eu dei 44 entrada (...), mas, eu sou boa conduta, faço tudo, vou pegá o paciente, todo mundo gosta de mim, ajudo na cozinha vô na casa da minha médica, cozinho lá, faço de um tudo pro doutor X. As sucessivas internações tornaram-se para ela um hábito, (...) daí, eu fiquei aviciada(...) cê sabe que a gente se habita, entendeu? Qualquer coisinha que eu tinha uma dorzinha: "eu vou me interna" (...) lá eu ficava à vontade(...) assim à vontade de cama assim, eu não tinha a preocupação com casa.

O que era fortalecido pela instituição, ela diz: Eu telefonava de qualquer canto e dizia Fulana [referindo-se à Assistente. Social]: "vou me interná". E ela dizia: "venha meu amor, não precisa nem pegá guia, tá aqui a sua vaga!”

Para Rotelli (1990) o manicômio é muito mais do que paredes, muros e grades. Desmontar essas instituições significa, fundamentalmente, desmontar estruturas mentais que dão sustentação e legitimidade ao modelo psiquiátrico centrado no hospital.

Nesse cenário, a família tem tido papel preponderante. A mãe de Davi (27 anos), um rapaz que sofre de epilepsia e alcoolismo, ao mesmo tempo em que manifesta o desejo de internar o filho para protegê-lo dizendo: Eu queria uma internação pro Davi, ele internado ficava melhor. (...)Porque, lá tá tomando o medicamen- 
to e não tá aqui bebendo(...) Lá na Ulisses Pernambucano [Hospital Psiquiátrico] é tão bonzinho (...)ele já internou no Zé Lopes, no Ulisses vária vezes(...) é bom porque, ele para mais de bêbe e volta pra casa direitinho, né?, parece desejar libertar-se do fardo ou de até mesmo puni-lo, quando diz na sua frente: Já falei pra Davi: "vou pegar um encaminhamento pra deixá você no Zé Lopes por vida porque, só assim eu vou tê paz!"

Para Foucault (1972) o internamento se justificaria assim duas vezes, num indissociável equívoco, a título de benefício e a título de punição. É ao mesmo tempo recompensa e castigo, conforme o valor moral daqueles sobre quem é imposto.

O uso do medicamento sem acompanhamento também é fato muito comum. O medicamento toma um grau de importância para essas pessoas que, em muitas vezes, supera a necessidade de outra forma de cuidado à saúde. Essa atitude, quando parte dos serviços de saúde, tem gerado sérios malefícios. É o que aconteceu com Neno (22 anos), segundo a irmã: Teve uma crise há poucos dias e eles conseguiram chamá o camburão da polícia pra levá ele no hospital. Daí, quando chegou lá não tinha vaga, fizeram a medicação nele, depois trouxeram ele pra casa. Daí, até uns dois dias ele ficou bem com o efeito do remédio, mas depois (...) ele começou a ter dor de cabeça, desmaio, agonia, o coração batendo muito forte. (...)Aí, a gente levou ele no Pronto-Socorro (...) eu vi que o negócio tava feio. Ele pediu: "me leve que eu tô morrendo, eu vô morre, eu vô morrê". Quando chegou lá, descobriu que foi por causa da medicação que ele tomou no Portugal Ramalho [Hospital Psiquiátrico], ficou como se diz? - Impregnado, né?

Para um pequeno grupo de alcoolistas, residentes no Pontal, o programa Alcoólicos Anônimos representa uma saída para a dependência. Para Cosme (47 anos), alcoolista em recuperação, foi sua tábua de salvação: se não fosse o A.A, eu não tinha nada(...) foi vinte dois ano de cachaça (...) se eu demorasse mais um mês de cachaça eu morria. (...) antes eu era um cachorro, agora eu sou um homem e o meu nome agora é Cosme!.

Em certos casos, a forma da família "enfrentar" o problema se revela em violência e abandono. A família de Davi, anteriormente citado, para protegê-lo das crises de epilepsia diz: "Quando ele adoece a gente amarra ele, a gente amarra com a corda, bota ele no quintal (...) pra gente ter paz; senão ele quebra tudo".
Para Neno (22 anos) as formas de lidar da família e do sistema de saúde para com seu sofrimento se reduzem ao puro abandono. Segundo a irmã: "A gente deixa de mão(...) ele é um mendigo(...) come na casa de um, come na casa de outro (...) a gente deixa ele de mão".

Para Agudelo (1997), ao aceitar esta lógica, a sociedade reconhece sua impotência para recuperar parte dos seus membros e opta, ativa ou passivamente, por autorizar, tolerar ou coonestar sua exclusão.

Por outro lado, o amor, a amizade, a religião e o entretenimento são tidos como recursos de alto valor terapêutico para a maioria dessas pessoas e, por vezes, é o único de que dispõem. É o caso de Gilda (50 anos), impossibilitada de realizar-se dentro das condições de vida que lhe foram impostas, buscou manter sua sanidade através da fé e da ajuda dos amigos: (...) a minha vizinhança me deu muito apoio (...) Foram muito bacana(...) o grupo da legião de Maria, o grupo da oração carismática (...) tudo era aqui junto comigo. Graças a Deus, nunca me deixaram sozinha(...) eu tive muito apoio dos meus vizinho e das minhas irmã em Cristo(...) foi só.

Para dona Berenice (52 anos), além do acompanhamento terapêutico regular, ela acha que (...) o que fez eu sair mais desse sofrimento foi a confiança e as amizades que a gente tem com as pessoas, isso é muito importante! (...)eu acho que as pessoas tem que se ajudar porque, tem pessoas que precisa da medicação mas, tem pessoas que eu aconselharia, que a palestra ajudaria muito mais, muito mais!

A atitude de dona Maria Rosa (49 anos) para com as pessoas que, como ela, vivenciam o adoecimento psíquico, traduz a importância que assume o diálogo para essas pessoas: $\mathrm{eu}$ consolo muito a pessoa que sofre nessa fase que eu passei. Eu tiro de tempo, eu converso. (...)Eu dialogo, né? Por que você sabe o que é dialogá?

Para Rúdio (1990) dialogar tem características de ser uma conversa não autoritária e nem dogmática, onde as pessoas se colocam em pé de igualdade quanto à participação de cada um. Essa igualdade se refere ao fato de que cada participante possui as mesmas oportunidades de ouvir e falar, de indagar e responder, de concordar e discordar, de emitir idéias, juízos e opiniões. Para ele, o "diálogo de ajuda” deve-se basear na certeza de que todas as soluções existenciais, necessárias para a vida do indivíduo, encontram-se dentro dele, ou então, que aí devem ser construídas. 
Vale ressaltar, que a palavra "palestra" apontada pela equipe e usuário em seus discursos toma conotações completamente diferentes. Enquanto para um é o desenvolvimento de uma técnica diretiva de orientação, para o outro é compartilhar sentimentos e idéias. Para os profissionais surge como uma forma de intervenção; para os usuários, como uma forma de interação e de diálogo.

As formas que essas pessoas desenvolvem para lidar com o adoecimento psíquico extrapolam, em muito, os limites da intervenção médica tradicional. Dona Berenice (52 anos), por exemplo, concilia várias estratégias: Eu procuro ir pra médica, conversar com ela, se divertir com as pessoas, sempre passear, a gente tem que dividir com as pessoas, procurar conversar, sair, se divertir. Busca, além disso, o envolvimento com outras pessoas, eu sou do grupo dos idosos, a gente sempre sai para passear (...). E, usufrui a companhia dos familiares, o que também me fortifica muito é que eu tenho muito neto, levo eles pra o colégio, eu mesmo vou apanhar, é uma maravilha!

3. A interação com a equipe local de saúde, segundo essas pessoas, infelizmente, se restringe à relação com as agentes de saúde, ao espaço da Unidade de Saúde e às ações individuais, onde o acolhimento e a escuta são tecnologias pouco exploradas pelos profissionais.

Para Guatari (1992) seria preciso arriscarse em novos territórios, mobilizar novos recursos em direções inusitadas. Redefinir o papel dos técnicos em saúde, abrindo perspectivas para que cada profissional possa diferenciar-se, inventar para si um modo mais autêntico de trabalhar. Repensar e ampliar a noção de terapeuta, a fim de abarcar a multiplicidade e a heterogeneidade de opções que a nossa subjetividade comporta. Dispor-se a acompanhar a aventura desses sujeitos na procura de uma existência mais livre e autônoma, criativa e flexível, aberta à negociação e ao conflito.

\section{Palavras finais}

Acredita-se que para cada contexto ou dimensão social há pontos cruciais de possível intervenção para a transformação do cuidado prestado a essas pessoas.

No nível individual, o cuidado deve se revelar no autoconhecimento e no conhecimento do outro, conhecer limites e possibilidades e aprender a respeitá-lo em si mesmo e no outro.
No contexto familiar, na tentativa de conviver e respeitar as diferenças, na proteção e amparo dos mais fracos e dependentes e na busca de relações abertas, flexíveis, democráticas há muita coisa que poderia ser feita pelos profissionais de saúde e, em especial, do PSF: aconselhamentos, diálogo, oficinas de expressão, desenvolvimento de trabalhos grupais, não somente para prevenir doenças, mas para inventar e reinventar a prática da atenção em saúde. Para tanto, precisa ampliar as suas relações com a comunidade retratada em toda sua rede social. Valorizar os recursos de auto-ajuda e de ajuda mútua. Ampliar os referenciais de escuta e do atendimento não diretivo. Buscar em outros setores sociais ajuda para o que se sente impotente. Desenvolver seu poder criativo em todas as direções, não se restringindo à monotonia de um trabalho meramente instrumental.

Aos gestores municipais de saúde cabe transformar a característica sanitária - campanhista - dada ao programa, descentralizando, não apenas ações expressas nos diferentes programas, mas promovendo a auto-gestão, a gerência participativa, o desabrochar da essência humana e não apenas da produtividade. Preparar seus profissionais para o relacionamento interpessoal e comunicação terapêutica. Favorecer e estar mais aberto à expressão das demandas subjetivas de usuários, familiares e profissionais. Construir uma rede substitutiva eficaz e suficiente, provida de profissionais envolvidos com o processo de mudança da atenção. Intensificar o processo de reabilitação psicossocial dos alcoolistas, que não se restrinja apenas ao Centro de Recuperação de Alcoolistas, mas que integre outros espaços sociais.

Ao poder político local, incentivar todo tipo de iniciativa cultural, que vise trabalhar os preconceitos com a pessoa doente e toda atividade solidária de grupos mais sensíveis e disponíveis.

No contexto político nacional, esse cuidado deve se revelar na adoção de uma política geral de desenvolvimento e de economia capaz de gerar uma cidadania emancipatória e não tutelada, guiada, sobretudo, em princípios de justiça social e de uma ética humanista. 


\section{Referências bibliográficas}

Agudelo SF 1997. Violência, cidadania e saúde pública. In Barata RB et al. (org.). Eqüidade e saúde: contribuições da epidemiologia. Fiocruz, Rio de Janeiro, pp. 39 62.

Amaral M 2000. Atenção à saúde mental na rede básica: estudo sobre a eficácia do modelo assistencial. Revista de Saúde Pública, 31(3). Disponível em: http:// www.sielo.br...fbetext? Acesso em: 10 abr.

Amarante P 1999. Manicômio e loucura no final do século e do milênio. In Fernandes MI (org.). Fim de século: ainda manicômios? IPUSP, São Paulo, pp. 47-56.

Bandeira M 1993. Reinserção de doentes mentais na comunidade: fatores determinantes de rehospitalizações. Jornal Brasileiro de Psiquiatria, 42(9): 491-498.

Boff L 1999. Saber cuidar: ética do humano - compaixão pela terra. Vozes, Petrópolis, $199 \mathrm{p}$.

Brasil 1999. Por uma política de saúde mental. Ministério da Saúde. Secretaria de Políticas de Saúde. Departamento de Políticas e Estratégias. Área Técnica de Saúde Mental. Brasília, 9pp., (fotocopiado)

Brasil 1999. Programas e projetos: saúde da família - documento. Disponível em: http://www.saúde.gov.br/ programas/pacs/psf.htm, 9pp. Acesso em 17/1/2000. Ministério da Saúde.

Campos GWS 1992. Reforma da reforma: repensando a saúde. Hucitec, São Paulo, pp. 143-193.

Código Internacional de Doenças/CID10 1998. Diretrizes diagnósticas e de tratamento para transtornos mentais em cuidados primários/Organização Mundial de Saúde; [tradução de Maria Cristina Monteiro]. Artes Médicas, Porto Alegre, 105pp.

Coordenação de Saúde Mental do Município de Maceió 1998. A reestruturação da assistência em saúde mental em Maceió. Boletim Informativo.

Danese MCF 1998. O usuário de psicofármacos num Programa Saúde da Família e suas representações sobre os serviços de saúde e os serviços religiosos. Dissertação de mestrado. Escola de Enfermagem de Ribeirão Preto. Universidade de São Paulo, 103pp.

Foucault M 1983. Vigiar e punir. Vozes, Petrópolis.

Guatari F 1992. Caosmosis. Manantial, Buenos Aires, pp. 11-46, 121-144.

Goffman E 1961. O modelo médico e a hospitalização psiquiátrica. Manicômios, prisões e conventos (2a ed.). Perspectiva, São Paulo, pp. 261-312. (Coleção Debates em Psicologia)
Kalil MEX (org.) 1992. Saúde mental e cidadania no contexto dos sistemas locais de saúde. HUCITEC/Cooperação Italiana em Saúde, São Paulo 237pp.

Kleinmann A 1978. Concepts and a model for the comparison of medical systems as cultural systems. Society Science \& Medical, n. 12, pp. 85-93.

IBGE. População do Brasil 1996. Disponível em: http:// www.ibge.gov.br. Acessado em 10/4/2000.

Levav I et al. 1989. Salud mental para todos en América Latina y e Caribe: bases epidemiológicas para la ación. Boletin de La Oficina Sanitária Pan-Americana, n. 107:196-219.

Lüdke M \& André M 1986. Pesquisa em educação: abordagens qualitativas. EPU, São Paulo, 99pp. (Temas Básicos de Educação e Ensino).

Melman J 1999. Intervenções familiares no campo da reforma psiquiátrica. In Fernandes MI (org.). Fim de século: ainda manicômios? IPUSP, São Paulo, pp. 173185.

Minayo MCS 1992. O desafio do conhecimento: pesquisa qualitativa em saúde. Hucitec/Abrasco, São Paulo, 269pp.

Oliveira GG 1998. O atendimento dos médicos em centros de saúde e a prevalência das desordens mentais. Dissertação de mestrado. Faculdade de Medicina de Ribeirão Preto. Universidade de São Paulo, 178pp.

Rogers CR 1971. Liberdade para aprender. Resumo e adaptação de Maria José Vidigal. Interlivros, Belo Horizonte $4 \mathrm{pp}$.

Rotelli F, Amarante P 1990. Reforma psiquiátrica na Itália e no Brasil: aspectos históricos e metodológicos. In Bezerra Júnior B (org.). Psiquiatria sem hospício: contribuições à reforma psiquiátrica. Relume-Dumará, Rio de Janeiro, pp. 41-67.

Rúdio FV 1990. Compreensão humana e ajuda ao outro. Vozes, Petrópolis, 96pp.

SMS 1999. Programa de Saúde da Família. Relatório das atividades desenvolvidas. Maceió.

Teles MLS 1992.O que é depressão. Brasiliense, São Paulo, $76 \mathrm{pp}$.

Veras E 1997. Introdução à crise da economia alagoana. EDUFAL, Maceió, 41p. (Série Apontamentos, 21).

Vieira MC 1997. Daqui só saio pó. Conflitos urbanos e mbilização popular: a Salgema e o Pontal da Barra. EDUFAL, Maceió, 96pp. 